\title{
ENVELHECIMENTO: MÚLTIPLAS IDADES NA CONSTRUÇ̃̃O DA IDADE PROFISSIONAL
}

\author{
Ageing: multiple ages in the construction of the professional age
}

\author{
Vanessa Martines Cepellos* \\ Gabriela Toledo Silva** \\ Maria José Tonelli***
}

\section{RESUMO}

O envelhecimento populacional é um fenômeno mundial que merece maior atenção dos Estudos Organizacionais. Nessa área, o envelhecimento é abordado a partir da idade cronológica, a qual, no entanto, se mostra insuficiente para apreender o fenômeno. Portanto, este estudo tem como objetivo identificar como os profissionais que atuam em organizações públicas e privadas constroem a concepção de envelhecimento. Para isso, foram entrevistados 14 profissionais, com mais de 50 anos, que tiveram os dados coletados e analisados por meio da grounded theory, a partir do olhar da realidade como socialmente construída. A pesquisa permitiu constatar que os profissionais não se reconhecem em sua idade cronológica, mas a partir de atributos e comportamentos desempenhados no trabalho. Essa condição leva à contribuição deste artigo, ao identificar a construção da idade profissional como uma das múltiplas idades do ambiente organizacional. A idade profissional é categorizada em idade burocrática e idade empresarial, referindo-se, respectivamente, à construção do envelhecimento para funcionários de organizações públicas e privadas.

Palavras-chave: Envelhecimento; Grounded-theory; Construção Social.

\section{ABSTRACT}

Population ageing is a global phenomenon and deserves greater attention from Organizational Studies. In this area, ageing is approached from the perspective of chronological age, which, however, is insufficient to apprehend the phenomenon. Therefore, the aim of this study is to identify how professionals working in public and private schools build a conception of ageing. For that, we interviewed 14 professionals over the age of 50 whose data was collected and analyzed through the Grounded Theory, based on the study of reality as socially constructed. The research allowed to verify that the professionals do not recognize themselves according to their chronological age, but in terms of the attributes and behaviors performed in their work. This condition was useful for this article, by identifying the construction of the professional age as one of many ages in the professional environment. The professional age is categorized into bureaucratic age and corporate age, referring to the construction of ageing for employees of public and private organizations.

Keywords: Ageing; Grounded-theory; Social Construction.

\footnotetext{
* Professora da Fundação Getúlio Vargas (FGV-EAESP). Doutora em Administração de Empresas pela Fundação Getúlio Vargas (FGV-EAESP). E-mail: vanessa.cepellos@fgv.br. ORCID: 0000-0001-6707-9751

** Pesquisadora do Centro de Estudos em Administração e Governo da Fundação Getúlio Vargas (FGV-EAESP). Doutora em Administração Pública e Governo pela Fundação Getúlio Vargas (FGV-EAESP). E-mail: gatoledosilva@gmail.com. ORCID: 0000-0003-4144-4057

*** Professora dos cursos de Mestrado e Doutorado em Administração de Empresas da Fundação Getúlio Vargas (FGV-EAESP). Doutora em Psicologia Social pela Pontifícia Universidade Católica de São Paulo (PUC-SP). E-mail: maria.jose.tonelli@fgv.br. ORCID: 0000-0002-6585-1493
} 


\section{INTRODUÇÃO}

$\mathrm{O}$ envelhecimento populacional é compreendido como uma das mais significativas tendências do século XXI (FUNDO DE POPULAÇÃO DAS NAÇÕES UNIDAS, 2012; UNITED NATIONS, 2015), tanto em países desenvolvidos como em países em desenvolvimento (GAVRILOV; HEUVELINE, 2003). Alguns fatores, como melhorias nas condições sanitárias e de saúde, permitiram o aumento da expectativa de vida - o que tornou o envelhecimento uma das grandes conquistas da humanidade, com implicações distintas para diversos domínios da sociedade (FUNDO DE POPULAÇÃO DAS NAÇÕES UNIDAS, 2012). Os dados demográficos referentes ao Brasil também indicam aumento na expectativa de vida da população e no número de adultos mais velhos no país nas últimas décadas (IBGE, 2013). A relevância da temática ainda está atrelada ao fato de que a estimativa para os próximos 40 anos é de que a população com 60 anos ou mais triplique em relação à população total (GIAMBIAGI; TAFNER, 2010; FRANÇA, 2011).

Uma das implicações do envelhecimento populacional, fundamental no debate em Estudos Organizacionais, Comportamento Organizacional e Gestão de Pessoas, é a alteração da força de trabalho (PHILLIPS; SIU, 2012). No Brasil os efeitos da transição demográfica afetam diretamente o tamanho e a composição da População em Idade Ativa (PIA), impactando na disponibilidade de mão de obra, pois a redução, no curto prazo, da proporção da população jovem acarretará, no médio e no longo prazos, em redução da PIA e no aumento da proporção dos idosos no ambiente de trabalho (NONATO et al., 2012). Apesar disso, a literatura acadêmica nacional, acerca do envelhecimento, ainda se mostra incipiente na área da Administração (LOCATELLI; FONTOURA, 2013, NASCIMENTO et al., 2016).

Um dos temas discutidos na literatura de Estudos Organizacionais trata da definição de quem pode ser considerado um trabalhador mais velho. Este tema se deve ao rápido envelhecimento populacional e às alterações do curso de vida. Mas, quase sempre, a idade é operacionalizada pela idade cronológica (ARMSTRONG-STASSEN; CAMERON, 2005; TAYLOR; WALKER, 1998; HENKENS, 2005; LORETTO; WHITE, 2006), ou a partir da autopercepção a respeito do envelhecimento (CEPELLOS, 2016). No entanto, o sentido de "velho" depende, em parte, do perfil demográfico das organizações ou ocupações das quais os empregados pertencem (NG; FELDMAN, 2012). Segundo Ng e Feldman (2012) há necessidade de que mais pesquisas, que abordem outras conceituações de idade nos estudos a respeito do envelhecimento, sejam realizadas. Para os autores a idade pode ser conceituada como uma variável independente nas pesquisas sobre organizações, uma vez que ela pode afetar os tipos de situações em que os indivíduos podem se encontrar e, por sua vez, influenciam a forma como eles são propensos a reagir.

$\mathrm{Na}$ medida em que a idade cronológica se mostra um instrumento insuficiente para identificar o envelhecimento do profissional, buscamos responder à seguinte pergunta de pesquisa: Como os profissionais, que atuam em organizações públicas e privadas, constroem a concepção de envelhecimento? Para respondê-la, realizamos 14 entrevistas em profundidade com profissionais com mais de 50 anos de idade que atuam em organizações públicas e privadas. De modo mais específico, buscou-se compreender como o envelhecimento é construído na esfera do trabalho a partir do conceito de idade. 
Este artigo apresenta, na primeira seção, a fundamentação teórica, contemplando os conceitos de envelhecimento e idade que serviram de base para este estudo. Na segunda seção, os procedimentos metodológicos, seguidos da análise dos dados e da discussão dos resultados e, por fim, as considerações finais.

\section{O ENVELHECIMENTO E A IDADE}

O campo de pesquisa sobre o envelhecimento é uma arena de múltiplos paradigmas, com abordagens teóricas diversas que operam e se transformam ao mesmo tempo. A complexidade e a diversidade do processo de envelhecimento exigem que o fenômeno seja apreendido sob muitas lentes (BENGTSON et al., 2009). De forma geral, as abordagens acerca do envelhecimento incluem considerações a respeito dos componentes estruturais sociais, psicossociais e comportamentais, além dos processos biológicos e genéticos (GANS et al., 2009). Na administração de empresas, estudos abordam desde a experiência do trabalho a partir da percepção do profissional mais velho (VASCONCELOS, 2015) até as práticas de gestão de idade voltadas ao profissional maduro (KOOJI et al., 2014).

A velhice, sob a perspectiva da Antropologia, é considerada uma categoria socialmente produzida, isto é, distingue-se entre um fato universal e natural, representado pelo ciclo biológico; e um fato social e histórico, representado pela variabilidade das formas com as quais se concebe o envelhecimento. Quando se aborda a velhice, na concepção de categoria socialmente construída, suas representações na sociedade e a posição social assumida pelos mais velhos são fornecidas pelos mais jovens e adquirem sentidos particulares em contextos históricos, sociais e culturais distintos. O mesmo ocorre com outras etapas da vida, como infância, adolescência e juventude. Além disso, essas fases não constituem propriedades que os indivíduos adquirem com o avanço da idade cronológica, mas são elaboradas simbolicamente com rituais que definem fronteiras entre idades pelas quais os indivíduos passam e que não são, necessariamente, as mesmas em todas as sociedades (DEBERT, 2006). A abordagem fenomenológica busca compreender os sentidos da vida social, enquanto o construcionismo contribui no entendimento das experiências dos indivíduos envelhecidos e da subjetividade do sentido da idade e do envelhecimento (BENGTSON et al., 2009). Sendo assim, o envelhecimento também é apreendido a partir da compreensão da idade.

Segundo Debert (2006) a idade cronológica está ausente na maioria das sociedades não-ocidentais. Já nas sociedades ocidentais, a idade cronológica é estabelecida por um aparato cultural, um sistema de datação, independente e neutro em relação à estrutura biológica e à incorporação dos estágios de maturidade. Para Kohli e Meyer (1986, p. 145), "[...] os estágios da vida são claramente definidos e separados e as fronteiras entre eles, mais estritamente organizadas pela idade cronológica". De acordo com Fortes (1984) a idade cronológica se apresenta como um mecanismo básico de atribuição de status (maioridade legal), de definição de papéis ocupacionais (entrada no mercado de trabalho) e de formulação de demandas sociais (direito à aposentadoria), entre outros. Esse mecanismo se mostra, portanto, flexível no que diz respeito à criação de novas etapas e à redefinição de direitos e obrigações; além disso, transforma a idade cronológica em um elemento simbólico, também econômico, já que permite estabelecer laços entre grupos homogêneos, que 
permitem que sejam agregadas outras conotações que não estão associadas à ordem de nascimento, estágio de maturidade ou geração. Entende-se, portanto, que a idade cronológica e o princípio geracional se apresentam como elementos da estrutura social e como valores culturais. No entanto, a idade cronológica se institucionaliza política e juridicamente e o princípio geracional a partir das referências familiares.

Lawrence (1996) alertou sobre as pesquisas a respeito da idade na literatura organizacional e sua relevância na área. Para a autora, a relevância do tópico está atrelada ao fato de que o modo como as pessoas experimentam o trabalho e de que forma este se relaciona com essas experiências representa uma das preocupações da teoria organizacional. Além disso, a ligação entre os objetivos do negócio e o planejamento de atividades dos profissionais se coloca primordial, pois, muitas vezes, os profissionais possuem diferentes idades e consequentemente compromissos, necessidades e valores diferentes. Por esta razão, entendemos que é necessário compreender como a idade é operacionalizada na literatura organizacional e verificar a existência de outras possibilidades para abordar este fenômeno.

\section{PROCEDIMENTOS METODOLÓGICOS}

A revisão da literatura mostrou que, de forma geral, os estudos relacionados ao envelhecimento, na literatura organizacional, utilizam a idade cronológica para compreender o fenômeno; a revisão evidenciou também uma lacuna de pesquisa, já que não foram identificados estudos que utilizassem outro tipo de abordagem para investigar o fenômeno.

Este estudo tem como objetivo verificar outras formas de identificação etária quando o envelhecimento é construído no espaço de trabalho. Para isso, foram realizadas 14 entrevistas com profissionais com mais de 50 anos que atuam em organizações públicas e privadas. Para a seleção dos participantes da pesquisa foi utilizada a rede de contatos das pesquisadoras. As entrevistas foram realizadas no ambiente de trabalho dos participantes, uma vez que privilegiamos o envelhecimento a partir do aspecto profissional dos mesmos. As entrevistas duraram, em média, uma hora, sendo codificadas com a utilização da ferramenta Atlas t.i.

As entrevistas foram transcritas, coletadas e analisadas a partir da abordagem metodológica de Strauss e Corbin (2008). Segundo Charmaz (2009) a entrevista é uma técnica que permite um exame detalhado de determinada experiência. Utilizou-se, como critério para a quantidade de entrevistas realizadas, a saturação das categorias que emergiram dos dados, de acordo com a orientação de Strauss e Corbin (2008). Segundo os autores, a ideia central na construção da teoria é coletar dados até que nenhum dado novo ou relevante pareça surgir em relação a uma categoria (STRAUSS; CORBIN, 2008). Para Strauss e Corbin (2008), a teoria fundamentada em dados sistematicamente coletados e analisados evolui durante a pesquisa real e exige contínua interação entre análise e coleta de dados. A análise dos dados ocorre em três etapas. A primeira é a codificação aberta, que é o processo analítico pelo qual os conceitos são identificados e desenvolvidos em relação às suas propriedades e dimensões. Por meio da codificação aberta, é possível fazer comparações e perguntas que vão guiar o pesquisador no campo empírico. Neste momento, portanto, foi realizada uma microanálise dos dados, linha a linha, a fim de identificar os 
principais conceitos ou códigos que colaborassem para a compreensão a respeito do fenômeno. Segundo Charmaz (2009), o estudo dos dados linha a linha possibilita o despertar de novas ideias a serem investigadas.

$\mathrm{Na}$ segunda etapa, realiza-se a codificação axial, que aprimora as categorias resultantes da codificação aberta, selecionando as categorias mais relevantes e colocando-as como fenômeno central para estabelecer relações entre as categorias e as subcategorias. Assim, os dados são agrupados por meio das conexões entre as categorias. Neste trabalho, os códigos identificados a partir da microanálise se vincularam em quatro categorias: idade moral, idade corporal, idade coletiva e idade profissional, na medida em que explicavam diferentes formas de se identificar com o envelhecimento.

A terceira etapa, da codificação seletiva, objetiva integrar e refinar categorias em um nível mais abstrato. 0 objetivo é elaborar a categoria essencial. Então, neste trabalho, as categorias que surgiram foram aprimoradas e identificou-se que elas compunham a categoria central das múltiplas idades, sendo esta, portanto, a categoria que explica como a concepção do envelhecimento é construída pelos profissionais.

Como abordagem teórica, esta pesquisa está pautada no construcionismo social, perspectiva que possibilita compreender uma experiência subjetiva (BURREL; MORGAN, 1979), como o envelhecimento (DEBERT, 2006). O construcionismo social apresenta como pressuposto o ser humano como construtor social, ou seja, como o criador de símbolos; visa apreender como a realidade social é criada (MORGAN; SMIRCICH, 1980); se concentra na forma como as pessoas agem e, finalmente, em como elas atribuem sentido às suas experiências (CUNLIFFE, 2003; 2008). De acordo com Spink e Medrado (2000), a produção de sentido é uma construção social pela qual as pessoas, por meio das relações sociais culturalmente e historicamente localizadas, constroem os termos - a partir dos quais compreendem os fenômenos ao seu redor, constituindo uma atividade social e dialógica. Por esta razão, vale ressaltar que a linguagem, durante as entrevistas realizadas para esta pesquisa, teve grande importância para a construção do sentido de envelhecimento para os profissionais das instituições públicas e privadas. Tanto durante a coleta dos dados, quanto em sua análise, averiguamos os termos utilizados pelos respondentes e os significados atribuídos às expressões utilizadas para caracterizar determinadas questões pertinentes ao envelhecimento e à idade.

\section{ANÁLISE DOS DADOS}

Nesta seção apresentaremos a análise dos dados coletados na tentativa de propor uma teoria substantiva acerca da construção do envelhecimento por parte dos profissionais entrevistados. O perfil dos respondentes pode ser verificado no Quadro 1. Foram entrevistados 14 profissionais: 7 atuam em empresas privadas, 7 atuam no serviço público. Dos entrevistados, 10 são mulheres e 4 são homens. A faixa etária dos respondentes está entre 50 e 67 anos. A média de idade é 55,8 anos. Os nomes dos entrevistados foram preservados, garantindo o anonimato e, por isso, serão utilizados pseudônimos. 
Quadro 1 - Perfil dos respondentes

\begin{tabular}{|c|c|c|c|}
\hline ENTREVISTADOS & TIPO DE ORGANIZAÇÃO & IDADE & SEXO \\
\hline Ana & Serviço público & 65 anos & Feminino \\
\hline Breno & Empresa privada & 52 anos & Masculino \\
\hline Carla & Serviço público & 67 anos & Feminino \\
\hline Daniele & Serviço público & 55 anos & Feminino \\
\hline Elaine & Serviço público & 50 anos & Feminino \\
\hline Fabiana & Empresa privada & 54 anos & Feminino \\
\hline Giovana & Empresa privada & 58 anos & Feminino \\
\hline Hélio & Serviço público & 57 anos & Masculino \\
\hline Ilana & Empresa privada & 54 anos & Feminino \\
\hline Júlio & Empresa privada & 57 anos & Masculino \\
\hline Luana & Serviço público & 57 anos & Feminino \\
\hline Mário & Empresa privada & 50 anos & Masculino \\
\hline Neide & Serviço público & 50 anos & Feminino \\
\hline Ofélia & Empresa privada & 55 anos & Feminino \\
\hline
\end{tabular}

Fonte: Elaborado pelas autoras.

Quadro 2 - Categorias, subcategorias e principais códigos

\begin{tabular}{|c|c|c|c|}
\hline CATEGORIA CENTRAL & CATEGORIAS & SUBCATEGORIAS & PRINCIPAIS CÓDIGOS \\
\hline \multirow{12}{*}{ Múltiplas idades } & \multirow{2}{*}{ Idade moral } & \multirow{2}{*}{ - } & Postura \\
\hline & & & Modos de agir \\
\hline & Idade corporal & - & Sinais do corpo \\
\hline & Idade coletiva & - & $\begin{array}{l}\text { Evento histórico, geracional e } \\
\text { coletivo }\end{array}$ \\
\hline & \multirow{8}{*}{ Idade profissional } & \multirow{4}{*}{ Idade burocrática } & Vínculo ideológico \\
\hline & & & Distância intergeracional \\
\hline & & & $\begin{array}{l}\text { Rompimento com a noção de } \\
\text { progresso }\end{array}$ \\
\hline & & & $\begin{array}{c}\text { Demissão e aposentadoria } \\
\text { simbólicos }\end{array}$ \\
\hline & & \multirow{4}{*}{ Idade empresarial } & Motivação por resultado \\
\hline & & & Conflito intergeracional \\
\hline & & & Ritmo de trabalho \\
\hline & & & $\begin{array}{l}\text { Fantasma da demissão e } \\
\text { recolocação }\end{array}$ \\
\hline
\end{tabular}

Fonte: Elaborado pelas autoras.

Durante a análise dos dados foi possível identificar as principais categorias e subcategorias que emergiram quando os indivíduos foram questionados a respeito do enveIhecimento na esfera do trabalho. A partir do Quadro 2 é possível verificar quais são elas. As 
relações entre categorias e subcategorias estão expostas de forma entremeada ao longo do texto, a partir da exposição das declarações dos entrevistados. Alguns tópicos se destacaram como pontos em potencial para discutirmos e aprofundarmos: a ideia de não-naturalidade da identificação etária; a existência de uma idade profissional - que é distinta da idade biológica ou da subjetividade privada do indivíduo; e a demissão simbólica, no setor público, como uma forma de afastamento de um funcionário de determinada função ou atividade sem demissão formal.

Ao estabelecer relações entre as subcategorias, foi possível perceber que a questão da identidade etária se fazia amplamente presente, articulando diferentes repertórios como formas de se situar no curso de vida. Além disso, notou-se que uma mesma pessoa poderia estabelecer diferentes formas de identificação, sugerindo, por exemplo, que, no mundo do trabalho, as atividades, as interações e os discursos tendem a dirimir a importância da idade; enquanto, na intimidade, ao olhar no espelho e ao colocar-se em situações de cortejo, é a imagem da pessoa fisicamente envelhecida que prevalece. Sob a perspectiva do envelhecimento, essas formas de identificação estabelecem conexões com as maneiras de agir: ser "velho" não é ter uma determinada idade cronológica, e sim se comportar de uma determinada maneira. $O$ envelhecimento se mostra relativo quando os entrevistados se identificam com semelhantes e diferentes.

Ana - Eu acho que tem uma parcela dos meus amigos que tão muito parecidos comigo. Mas tem uma parcela que não. Que eu sinto que são pessoas que dizem "não, tô veeeelho!" e que você percebe que a pessoa tá cumprindo esse papel de virar velho, sabe, eu acho uma pena. Acho uma pena. Mas posso te dizer que nesse momento a maior parte dos meus amigos não tá nessa vibe, como vocês dizem.

Ao considerar que essa identidade acaba orientando as formas de agir, de estabelecer semelhantes, de separar lugares em que pode se manifestar ou não, essa identidade deixou de ser apenas uma autoimagem, um aspecto isolado do envelhecimento que se pretendia estudar, para cumprir uma função mais interessante de ser investigada, que é o processo de mobilização de identidades etárias, aqui denominado criação de idades, ou seja, outras idades, referenciadas por elementos que não têm por base a idade cronológica. São idades qualificadas, específicas e múltiplas, que ajudam os indivíduos a se posicionarem no curso da vida em diferentes situações sociais. Especificamente são componentes do estabelecimento de uma esfera propriamente profissional, cuja temporalidade, ciclos e marcadores dão a ela contornos específicos, criando múltiplas idades.

\subsection{AS MÚLTIPLAS IDADES}

Por que múltiplas idades? A partir dos dados, foi possível perceber que a voz dos entrevistados cria diferentes maneiras de estabelecer a idade dos profissionais. Frequentemente, os entrevistados não reconhecem que a idade cronológica é um fator relevante de identificação. 0 que ocorre é que, embora a passagem do tempo seja inexorável, ela não se reflete no reconhecimento do efeito desta transição. 


\begin{abstract}
Ana - De fato, você vai vendo a sua vida passar e isso faz uma marca em você, entendeu? Eu faço, amanhã, 65 anos! Não é pouco 65 anos. E eu me olho no espelho e digo - mas como assim 65 anos? Entendeu? Eu me sinto com muito menos, nesse sentido de ter curiosidade pelo mundo, de ter vontade de fazer coisas [...]. E eu acho que tem uma parcela da população que, de fato, fica velha, entendeu? De fato, fica - às vezes eu encontro pessoas que têm menos idade do que eu e que tão muito mais detonadas, mas muito mais. Não só porque a vida fez isso, porque são pessoas de mais baixa renda e tal, mas pessoas mesmo na minha classe, que envelhecem e que ficam mais lamentosas, que ficam um pouco mais deprimidas, que ficam mais sem função; então, de fato, acho que a terceira idade existe.
\end{abstract}

O lamento, a depressão e a falta de função são fatores que tornam a pessoa "veIha" - esse envelhecimento que muitos dos nossos entrevistados, até mesmo por estarem trabalhando, dizem não se identificar. É o envelhecimento como profecia, como algo que só se realiza quando a pessoa se pensa "velha".

Luana - Eu acho que as pessoas entram [no serviço público] já envelhecidas. Ou ficam envelhecidas pela forma como ele se move, como o serviço público se move. Entendeu? [...]. Então, eu acho que o envelhecimento é aquela visão que você tem errada, pra dentro do serviço público. A gente precisa mudar isso. E isso é difícil de mudar, não sei por quê.

Embora as pessoas não se reconheçam com a idade cronológica, elas distinguem que velhos são os "outros", mesmo que esses "outros", identificados como amigos, colegas de trabalho e familiares, possuam a mesma idade que elas.

Breno - Eu sou um pouco fora da curva porque apesar de ter 50 anos, eu acordo todos os dias 4 h30min da manhã e vou dormir às $2 \mathrm{~h}$ da manhã todos os dias. Eu tenho um pique bom, humor bom, eu não tenho preguiça, às vezes eu vejo jovens com 20 e poucos anos se lamentando, e eu não tenho muito o que lamentar, eu também sou um pouco fora da curva [...]. Os mais maduros não conseguem acompanhar a tecnologia, eu consigo porque eu adoro, mas esse pouco é pouco... e eu tenho amigos da minha idade que não conseguem acompanhar absolutamente nada, não faz nem ideia do que seja, a distância está ficando muito grande, alguém precisa encurtar isso.

A manifestação dessa não-identificação com o envelhecimento não só é explícita como reforçada. A capacidade, a vontade e a facilidade de lidar com novas tecnologias foram muito presentes nas entrevistas, talvez porque hoje elas tenham invadido o mundo privado, não são citadas apenas como ferramentas de trabalho: aprender e acompanhar as mudanças são atitudes que também afastam os entrevistados dessa velhice indesejada.

Fabiana - No meu sentido, tem muito mais valor esse conhecimento do que propriamente a idade. Eu estou oxigenando o cérebro o tempo inteiro, estou sempre pesquisando, leio, se eu produzo lendo ou escrevendo vai aumentando meu conhecimento, minha capacidade de agregar valor ao meu cliente. 
Esse aspecto privado da tecnologia também apareceu como um marcador de diferenças, não pela capacidade de aprender, mas novamente pelo julgamento de uma conduta inadequada - dessa vez não do velho, mas do jovem.

Fabiana - Isso, por exemplo, é uma coisa que a gente que não é dessa geração digital tem menos familiaridade, gosta menos e tem mais dificuldade, então, eu, por exemplo, dizia que eu nunca ia ter Facebook, por exemplo, e não é porque é difícil aprender ou tenha algum problema em relação a não saber se virar no mundo tecnológico. Não! Porque isso poderia se aprender. É muito mais em função do comportamento que tá por trás de você ser um usuário do Facebook e não faz falta e muitas vezes eu não aprovo.

A lógica do estabelecimento da própria idade como diferente dos outros envolve esses julgamentos, os comportamentos adequados e inadequados. Frequentemente, o "se sentir jovem" tem a ver com o desejo de não parar de trabalhar. Velhos são aqueles que querem se aposentar logo:

Carla - Eu não senti essa parte [da idade] viu, pra falar a verdade. É como se tivesse 25 anos ainda. [...] Acho que depende de seção e de chefia também. Porque tem lugar que tem gente que fala assim "ai quero aposentar logo" né, aqui pelo menos eu vou aposentar compulsoriamente, mas sem problema assim.

Em outros momentos, o envelhecimento é entendido como uma postura, é uma idade moral que se revela, apontando para valores e modos "corretos" ou esperados para agir, por vezes, contrários ao desejo pessoal:

Carla - Roupas que você vai comprar que eu acho lindo e fico pensando que estou um pouco fora da idade de vestir esse tipo de roupa. Coisas assim, te fazem lembrar que a idade tá ali porque, apesar de você ser muito descolada e tal, tem um limite que você vira ridícula. Tem. Não posso sair de minissaia. É ridículo. Muito embora eu me sinta ainda muito desejosa disso.

Embora os entrevistados tenham se mostrado resistentes a verbalizar que o envelhecimento havia chegado para eles, em grande parte das vezes, a concepção do envelhecimento surgiu quando questionados a respeito dos sinais que o corpo notifica. Nestes momentos, os entrevistados se colocaram no papel de fragilizados e pontuaram, exatamente, os indícios do envelhecimento. É a idade corporal declarada pelos indivíduos.

Daniele - A parte física sim, isso é inegável, seu físico já não corresponde aquilo... Por exemplo, antes eu ficava em uma inspeção das 8 às 17 horas de pé, fisicamente você tem uma restrição.

Elaine - $O$ campo de visão é pequeno e a posição da coluna não é confortável. Com o passar dos anos, a gente passa a desenvolver L.E.R, a ponto de ser considerada uma profissão insalubre. 
Notou-se também que o envelhecimento é reconhecido pelos entrevistados como uma relação histórica, geracional e coletiva, que não tem necessariamente a ver com a idade individual. É a idade coletiva declarada entre os indivíduos.

Elaine - 0 que eu noto muito hoje em dia é o seguinte: eu trabalhei no mercado imobiliário que teve um crescimento muito forte de 2004 para frente, porque muitas empresas abriram capital, então, a gente teve uma mudança do perfil das pessoas que trabalham nesse mercado.

Fabiana - Eu não sei se foi uma mudança em relação à idade ou se foi em relação à natureza mesmo do trabalho né, e aos modos de se trabalhar nessa coisa de produção da imprensa, do jornalismo.

A partir dos pontos apresentados, verificou-se que, de forma geral, os indivíduos não se identificam com a idade cronológica que possuem. Posto que há situações em que o sujeito não reconhece apenas sua idade cronológica na esfera do trabalho, com que tipo de idade ele se identifica? Afinal, de qual idade os entrevistados estão falando? Será que existe algo além da idade cronológica? A partir das entrevistas, constatou-se que sim. Relatos mostraram que há identidades etárias construídas por meio de referências do mundo do trabalho. Identificou-se, então, uma idade profissional, ou seja, uma idade construída profissionalmente que posiciona o indivíduo no mundo do trabalho de acordo com determinados critérios.

A idade profissional não é pautada pela cronologia. Na idade profissional, os "atributos", a "formação", o "preparo, a "questão psicológica", o "modo de agir" ou a "postura" são colocados como mais importantes do que a idade cronológica na definição de situações que são costumeiramente associadas à idade. Essa manobra, de colocar outros fatores à frente da idade cronológica, é similar à elaboração das justificativas para não-identificação etária apresentadas anteriormente e abrange, ainda, questões como "atualização tecnológica", "bom humor", critérios que organizam uma espécie de autoimagem etária.

Elementos de ruptura, como viuvez, ter filhos e assumir cargos dentro da empresa, surgiram como eventos significativos de história e temporalidade. No âmbito profissional, no entanto, elementos de continuidade, relacionados a eventos como projetos que deram certo e o aprendizado contínuo, apresentaram-se como fatores que garantem a permanência do indivíduo em uma condição de não-envelhecimento. Ser ou estar "atual", fazendo parte ativamente do tempo presente parece um valor constante entre nossos entrevistados.

Giovana - Tem que estar sempre se aperfeiçoando, aprendendo, lendo, não pode ficar parado, fazendo sempre a mesma coisa. O mundo de hoje é tudo muito rápido. Sempre gostei de fazer cursos, aprender coisas novas, tenho certificado de todo tipo. Em primeiro lugar os mais velhos têm que estar sempre se reciclando para poder ter uma oportunidade e depois incentivos pelo governo e donos ou responsáveis pelas empresas em dar a oportunidade.

Portanto, os critérios para definição da idade profissional estão ligados à capacidade e à disposição para estar atual e são construídos em oposição às construções de idade ligadas à vida privada: o trabalho aparece como imagem positiva aos profissionais mais 
velhos, como elemento que coloca o indivíduo numa categoria ativa e positiva; enquanto na vida privada há espaço para manifestações mais negativas.

Ana - No mundo do trabalho, as pessoas que trabalham 8 horas por dia, que são ativas, o envelhecimento ele é mais... ele se evidencia menos... e ele é reconhecido por quem está envelhecido, por quem olha de fora, menos como se fosse uma ameaça.

Entrevistadora - Então, dentro do trabalho ele [envelhecimento] acaba sendo positivo?

Ana - É, ele fica com a parte boa do envelhecimento.

Ao passo que o trabalho res-significa o envelhecimento, o não-trabalho surge como imagem negativa aos profissionais mais velhos. Os entrevistados associaram a questão do não-trabalho a elementos como morte, perda de função na sociedade e congelamento.

Daniele - Quando você para de trabalhar, você deixa de ter uma função na sociedade; isso é meio complicado, eu acho, porque a pessoa fala - você não faz nada, você está folgada, quer dizer, mas você fez a vida inteira.

Ilana - Eu acho que se a pessoa pára, ela congela, morre; você tem que estar sempre aprendendo, renovando, estar em contato com as novidades.

Outro critério que orienta o estabelecimento da idade profissional diz respeito à postura frente ao trabalho. Frequentemente, o envelhecimento não é reconhecido na esfera do trabalho, ele desaparece simbolicamente e dá lugar a comportamentos universais de qualquer profissional, seja ele velho ou não. 0 envelhecimento se dissipa e se reconfigura com base nas competências do profissional e na sua postura frente ao trabalho.

Entrevistadora - Você acha que a idade é um fator de diferenciação entre as pessoas [no trabalho]?

Carla - Acho que não. Se cumpriu dever da pessoa não tem assim diferença, né. Acho que depende do comportamento do funcionário mesmo, depende de si mesmo. No meu caso, fui beneficiada. Tem uns colegas que já reclamam, né, que não é compreendido, que não é assim, não conseguem alguns cargos alguma coisa reclama. Mas também não mostra, não demonstra muito assim que atividade assim, como diz, meio paradinho, né, pra falar a verdade. Acomodado.

Ilana - Eu acho que o que não pode ser misturado é a sua idade cronológica com a sua idade profissional, a idade construída profissionalmente, porque você pode ter uma pessoa mais jovem acima de você que tem atributos diferentes de você e uma formação diferente, e mais capacidade, mais experiência e ok. E isso não tem problema nenhum.

Outro ponto recorrente citado nas entrevistas foi o valor da experiência: ela é um fator relevante para os entrevistados mais velhos, sendo um elemento que colabora na construção ideológica do que a idade representa ao indivíduo. Porém, as visões sobre experiência trazem também critérios relacionados à relação intergeracional no ambiente de trabalho 
Para abrir a discussão a respeito da experiência e seu significado, é pertinente enfatizar a declaração "quanto mais idade, mais experiência", que foi citada diversas vezes durante as entrevistas. Ao mesmo tempo em que esta frase é citada, em seguida, os entrevistados pronunciam que "não é questão de idade, é questão de preparo". Compreende-se que isto não é uma contradição à ideia inicial, é somente a manifestação de que existe uma idade subjetiva que não confere com a idade cronológica. Sendo assim, o valor da experiência depende dos outros critérios não-cronológicos, como atualização, adequação e preparo. Neste sentido, a partir dos relatos, foi possível verificar que a experiência está vinculada também ao conjunto de posições e modos de agir considerados adequados: é à experiência que se credita a possibilidade de agir adequadamente em alguns contextos - mas não necessariamente.

Júlio - Então, eu acho que a grande mensagem não é ser jovem ou ser velho, é estar preparado. Eu acho que a idade pode ser mais importante, menos importante, mas eu acho que tem muito mais a questão psicológica do que efetiva.

Luana - Eu acho que o envelhecimento melhora a gente muito. Eu sou muito melhor hoje do que eu fui ontem. Eu acho que o envelhecimento faz bem pra todos. Fora ou dentro do serviço público. Experiência é uma coisa necessária e fundamental para você fazer um bom trabalho. Inexperiência nos deixa mais aguerridos, mas fazendo mais besteiras. A experiência já nos deixa menos aguerridos, mas com menos possibilidade de fazer bobagem. Mas faz parte do jogo.

Além da experiência, outro fator amplamente discutido em nossas entrevistas foi a aposentadoria e seus significados. Embora a aposentadoria tradicionalmente represente um momento em que o indivíduo deixa de trabalhar e "retorna" ao aposento, nossos entrevistados se opuseram a este comportamento. A aposentadoria parece ser vista como uma atitude mecânica e operacional, mas que se transforma durante sua transição. A maioria dos entrevistados alegou que, ao se aposentarem, pretendem continuar atuando na mesma área de trabalho ou com outras atividades. As motivações para o trabalho contínuo são diversas, desde caracterizar-se como uma pessoa ativa, até mesmo, por questões financeiras. A expectativa de trabalho chega a ser até 70 anos de idade. A aposentadoria está associada ao recomeço de uma nova atividade. 0 indivíduo envelhece e se afasta em busca do rejuvenescimento, mesmo que essa distância implique em um novo trabalho.

Ofélia - Eu quero sair deste trabalho. 0 nome é se aposentar porque será assim mecânica operacionalmente, né, mas eu tenho vontade de fazer, eu me sinto como se eu tivesse 20, 20 é um pouco de exagero, mas 30 anos. Sabe, com vontade de pensar novos projetos, pensar novas coisas. Agora, é tem uma coisa curiosa em relação a isso, paradoxalmente, eu queria muito me aposentar e isso me rejuvenesce. Do meu pensamento, me aposentar seria me rejuvenescer, ou seja, me reinventar de novo. Eu teria que tá aí caçando, queria trabalhar com fotografia, queria fazer projetos alternativos de educação infantil umas coisas mais, uma coisa que eu brinco - eu queria fazer uma escola de perguntas e não de respostas - sabe, brincadeiras assim? Isso me pilha, me potencializa, sabe? 
De forma geral, entre os critérios para o que foi denominado de idade profissional, destacam-se (1) a capacidade e disposição para estar atual; (2) a atividade de trabalho como positiva em relação à inatividade; (3) as diferentes dimensões da experiência e, finalmente, (4) a aposentadoria como marco de mudança e não de fim. Neste trabalho, nos concentramos no conceito de idade profissional, categorizado em conceitos de idade burocrática e idade empresarial, como peculiaridades na construção do envelhecimento de profissionais que atuam no setor público e empresa privada.

\subsection{IDADE PROFISSIONAL COMO UMA IDADE BUROCRÁTICA}

Embora nossas análises não tenham centrado nas diferenças entre o envelhecimento nas organizações públicas e privadas, alguns pontos tomam forma diferente quando se referem à esfera pública. Na esfera do trabalho, a idade profissional assume outros formatos; um deles é o que chamamos de idade burocrática. A idade burocrática se apresenta, via de regra, para os funcionários públicos. É uma idade engessada, que se insere em uma "cartilha invisível", que acompanha uma estrutura predeterminada pelos órgãos públicos.

Em relação à motivação, a maior parte dos entrevistados do setor público alegou ter vínculo de interesse ligado ao trabalho, tornando preponderante o vínculo ideológico com a atividade. São motivações orientadas por ideais, conviç̧ões ou desejo de mudar a realidade social. Trata-se de discurso justificador da motivação para o trabalho e, em alguns casos, mostra-se como a principal razão em ter ficado tanto tempo no trabalho e estar trabalhando ainda hoje.

Elaine - Gosto do meu trabalho, em especial do contato com o ser humano. Sinto-me satisfeita em poder resolver o problema de saúde que as pessoas enfrentam, principalmente dos mais necessitados. As minhas motivações mudaram ao longo do tempo. Antes eu não tinha tanta motivação quanto tenho hoje. 0 que mudou foi o relacionamento com a chefia, os cursos de capacitação que eu realizei etc... que fazem com que eu trabalhe com mais prazer e segurança.

Outro ponto de destaque na discussão da idade burocrática refere-se à distância intergeracional existente no trabalho daquele que atua em organização pública. A entrada de funcionários neste tipo de organização não se apresenta como um ciclo contínuo de renovação, o que acaba por evidenciar ainda mais os efeitos do envelhecimento. No serviço público, a intergeracionalidade surge com o hiato entre concursos, o choque entre gerações é etariamente mais bruto.

Luana - O problema do serviço público, quando se fala de envelhecimento, é você não renovar, não ficar em constante renovação da força de trabalho. Você deixar lacunas muito grandes. Aí sim, não é bom, porque daí você convive com gerações muito diferentes, o que em termos de recursos humanos, hoje a gente convive com esse problema. É complicado você gerir esses distanciamentos. Principalmente se você não se atualiza nessas questões, principalmente se você é dirigente. Entendeu? Então, eu acho que isso muda. Mas se o serviço público não deixasse que essas lacunas ocorressem, o enve- 


\begin{abstract}
Ihecimento não seria um problema. Hoje, é problema. Ele é problema, porque criou essa lacuna enorme de tempos. E com isso nós não temos pessoas preparadas para assumir e temos pessoas que já estão cansadas querendo ir embora. Eu estou aposentada. Eu estou querendo ir embora. Ir embora no bom sentido. Não quero, não sou uma pessoa que quer parar, que quer parar de trabalhar. Mas eu acho que eu tenho que dar espaço. Já deveria ter outras pessoas tomando espaço.
\end{abstract}

O hiato existente entre os concursos e a entrada de novos funcionários por meio de concursos públicos pode levar a uma característica peculiar das organizações públicas: o envelhecimento em conjunto. $O$ envelhecimento da organização consoante ao envelhecimento social. Neste caso, o envelhecimento profissional se camufla no envelhecimento da organização. As pessoas não se percebem envelhecendo. É uma idade profissional, burocrática, coletiva e sincrônica. No setor público, um dos elementos de desmotivação entre os profissionais é a falta de um plano de carreira, o que acarreta um sentimento de rompimento com a ideia de progresso, de mérito, de reconhecimento. 0 profissional é anulado da atividade de trabalho e o que resta é a estrutura do serviço público. A idade burocrática se manifesta nesse momento em que a invisibilidade vem à tona aos olhos da estrutura.

Daniele - 0 que desanima o pessoal mais antigo é que você não tem uma carreira, uma estrutura de carreira, então você entra no primeiro ano. Você continua 30 anos sem ter aumento de salário, quer dizer de engenheiros e arquitetos, né, sabe, isso também tem diferença na minha carreira, se a pessoa acaba de entrar e você está lá, a diferença de salário quase não existe, porque você também a cada 5 anos ganha $5 \%$ então não é coisa que se diz: tive aumento de salário porque eu melhorei, eu aprendi, obedeci - não, é um direito de todo mundo, isso desanima muito, eu acho.

O indivíduo mais velho, no setor público, fica sujeito a algumas situações um pouco diferentes daquele no setor privado, quando ele mesmo se "aposenta", mesmo estando trabalhando, e quando ele é "aposentado" ou demitido por outrem, ainda que continue trabalhando. No primeiro caso, é como se a pré-aposentadoria fosse um espaço de tempo em que nada acontece, é um momento de espera. Na pré-aposentadoria, o profissional entra no ócio, ele se acomoda, é um período em que ele não se afasta, mas também não produz. 0 indivíduo também pode ser "demitido" de alguma função sem ganhar nenhuma outra para substituir. Foram ainda narradas formas de afastar o profissional de uma determinada atividade, os chamados "encostados" ou "pendurados na brocha", expressões essas que foram utilizadas por diferentes entrevistados para enfatizar profissionais que são agrupados, até mesmo fisicamente, por exemplo, em salas diferentes, a fim de ficarem isolados e não causarem conflitos ou problemas.

Daniele - Você não pode mandar o funcionário embora, a punição é um pouco complicada, você leva muito tempo, então fica uma coisa presa na outra e a coisa não deslancha, é uma questão administrativa mesmo, você fica pensando que é para não funcionar mesmo [...]. Você não devia punir, mas devia ser o inverso, você deveria premiar quem trabalha, porque a punição é meio complicada no Estado. 
Em suma, a idade burocrática se produz orientada por (1) um discurso motivador baseado no bem comum; (2) hiato intergeracional e envelhecimento das organizações; (3) rompimento com a ideia de progresso e (4) processos de demissão e aposentadoria simbólicos.

\subsection{IDADE PROFISSIONAL COMO UMA IDADE EMPRESARIAL}

No setor privado, a idade profissional também assume suas peculiaridades. Denominamos a idade profissional, neste caso, de idade empresarial. A idade empresarial, se manifesta durante as relações e conquistas no ambiente de trabalho, durante a concorrência e, até mesmo, na carga de trabalho oferecida aos profissionais. No setor privado, a intergeracionalidade não se apresenta como distância, como no setor público, e sim como fonte de conflito, especialmente quando o profissional mais velho é subordinado a um profissional mais jovem ou quando o preconceito com o mais velho é evidente durante as relações de trabalho. Apesar dos conflitos, a diversidade de idades pode ser um ponto positivo, desde que algumas medidas sejam tomadas para viabilizar o convívio destas gerações. Os entrevistados pensam que a área de Recursos Humanos deveria agir em prol deste convívio.

Breno - O conflito é muito grande. As gerações que conflitam, da geração minha, com quem tá se formando agora, que pegou internet inteira, essa fase do computador, do telefone, todas essas coisas da internet... então, tem até uma nova geração e essa nova geração... se a Y já não tinha muita paciência, essa tem menos ainda, ela já entra perguntando "o que você vai fazer comigo nos próximos 3 meses?". Na minha época era assim: "será que daqui 5 anos vou ter algo legal?". O mais velho acha que está sendo desprezado. 0 mais novo acha que o velho não sabe nada. [...] Cabe, às empresas, trabalhar esses dois níveis muito importante para a empresa fazer com que eles se conversem, se entendam... Se a preocupação do RH é a empresa, então faça esses caras conversarem, eles são importantes pra empresa, eu não quero perder ninguém.

As motivações, em grande parte das vezes, estão relacionadas aos resultados conquistados durante as atividades de trabalho e não tanto ao processo de trabalho, como no setor público.

Fabiana - Eu acho assim, me sinto supervalorizada, até por conta do boca a boca, das mensagens que as pessoas deixam no Facebook, Linkedin, telefone, ou de repente, eu tô aqui em casa e recebo um mimo, a pessoa agradecida pelo resultado do trabalho, enfim... Então, assim, a questão de ser valorizada é muito importante, porque isso te dá estímulo, força pra continuar, que estou no caminho certo e outra coisa também, o resultado disso, o que eu faço, é o que eu gosto de fazer, então eu coloco um carinho naquilo que eu faço.

As queixas ligadas à idade se baseiam no cansaço, na pressão e no ritmo de trabalho exigido no setor privado; os entrevistados apresentaram resistência ao comentarem que tinham sofrido dificuldades por conta da idade. 
Giovana - Elogiavam o currículo, mas diziam que estava fora da faixa etária. Foi uma época em que aceitavam até 35 anos. Diziam que tinha que ter até 35 anos.

A idade empresarial se pauta, portanto, mais especificamente, por (1) conflito intergeracional; (2) motivação gerada por conquistas, (3) pressão e ritmo exaustivo de trabalho; (4) o fantasma da demissão e recolocação de trabalho. Em síntese, as categorias que surgiram da análise das entrevistas permitiram demonstrar que a construção do envelhecimento na esfera do trabalho se dá a partir de diversas dimensões que não estão ligadas somente à idade cronológica, mas que estão inter-relacionadas e representam eventos e critérios que se refletem em uma identificação etária construída profissionalmente.

\section{DISCUSSÃO DOS RESULTADOS}

Inicialmente nosso objetivo era entender como as pessoas percebiam seu enveIhecimento no ambiente de trabalho. Essa pergunta partia do pressuposto que as pessoas de fato "percebem" seu envelhecimento e se identificam com esse processo. À medida em que as entrevistas foram realizadas, notamos que os entrevistados hesitavam, contornavam, questionavam e relativizavam a relevância da idade para eles. Concluímos, provisoriamente, que esse pressuposto estava equivocado e que a identidade etária não era nem óbvia nem necessária. Passamos então, a prestar atenção nos discursos que sustentavam a existência ou não de uma identidade etária, nas maneiras de reconhecimento e rejeição, suspeitando que, mesmo diante das declarações verbais sobre sua provável irrelevância, a idade teria algum papel para desempenhar na vida profissional de nossos entrevistados. Então, percebemos que o problema não era se identificar com a idade, e sim com uma concepção específica de idade, tornada preponderante pelo senso comum: a idade cronológica. Essa idade, cuja ordem de grandeza se mede pela contagem numérica do tempo de vida, situa a pessoa num ciclo linear do nascimento à morte e estabelece relações de acordo com a posição nessa linha entrecortada por anos. E essa idade simplesmente não é suficiente para abarcar a riqueza de nuances que nossos entrevistados usaram para se situar nos ciclos e temporalidades por eles descritos: sua "posição" nessa linha imaginária, que determina quem vem antes de quem e depois de quem (como os mais velhos e os mais novos, na idade cronológica), traz relatos de como os antepassados lidavam com a velhice, como os amigos se portam, como o trabalho instiga, como se acham jovens, como dão sentidos à possibilidade de aposentadoria, como referenciam sua vida profissional; enfim, é uma posição temporal marcada por experiências de ordens não pertencentes necessariamente às etapas da vida.

Então, o que encontramos no processo de análise foi que as pessoas criam as idades com as quais se identificam e também aquelas que rejeitam. Elas se sentem com menos idade e apontam que os velhos são os "outros". Neste processo, negam que tenham posturas relacionadas à velhice e exibem comportamentos tidos como da juventude, não havendo, portanto, apenas a idade cronológica. Passamos a nos perguntar, então: Como os profissionais constroem o envelhecimento? A partir desta pergunta de pesquisa, conduzimos as entrevistas em busca da idade com a qual os participantes se identificavam. A elaboração 
da teoria fundamentada nos dados desta pesquisa tem como ponto de partida, portanto, a não-identificação com a idade cronológica. Nos dados, entretanto, surgiram diferentes concepções de idade, como idade moral, idade corporal, idade coletiva e idade profissional, categorias que refletem as diversas formas pelas quais os entrevistados se identificam e que constroem a concepção de envelhecimento. Inferimos, portanto, que as idades são múltiplas e organizadoras da experiência do envelhecimento, identificadas, neste estudo, como a categoria central que explica como os profissionais mais velhos atribuem sentido ao fenômeno. Essas diferentes idades, integradas, formam o que chamamos, neste trabalho, de múltiplas idades. A concepção de múltiplas idades surgiu, principalmente, da necessidade de suprir a diversidade da própria fala dos entrevistados, mas segue a noção de política ontológica de Mol (1999, p. 75), supondo que se "[...] a realidade é feita, se é localizada histórica, cultural e materialmente, também é múltipla. As realidades tornaram-se múltiplas"; as idades, quando localizadas e qualificadas, também podem ser múltiplas.

Ao apresentarmos as múltiplas idades, nos deparamos com algumas nuances que se mostraram relevantes para compreender o que o envelhecimento representa para os profissionais entrevistados. Primeiramente, verificamos que a idade cronológica parece importar mais para os outros do que para eles. Os critérios pessoais e profissionais de estabelecimento da situação no curso de vida são mais complexos. O exercício de delinear a idade profissional, categorizada em idade burocrática e empresarial, nos mostrou que há muito mais sob o invólucro da idade do que imaginávamos. Esse retrato, ainda, tende a mudar rapidamente, de acordo com respostas a essas pressões e contradições entre o que se espera do profissional e o que ele espera fazer dentro de sua idade quando qualificada. Portanto, é uma pesquisa que reflete um momento histórico específico, como a própria vida dos profissionais que entrevistamos.

Em todas as entrevistas se fez presente o comentário sobre a inexorabilidade da saúde, das condições físicas para poder pôr em prática essa idade repleta de significados descrita pelos profissionais. As doenças e restrições no domínio das faculdades corporais são constitutivas de uma idade inadiável, de um momento a ser evitado, mas que se faz presente em todos os discursos. Essa fragilidade mostra-se imperativa, embora existam tentativas de driblá-la, negando o encontro com o envelhecimento. Continuar trabalhando, aprendendo e estudando são manobras para que se lute contra a construção do envelhecimento. Limitações físicas também são desviadas por meio de uma nova condição de trabalho, aproveitando a tecnologia e os novos formatos organizacionais.

Mas, em qual plano as múltiplas idades se estabelecem? Apesar de apresentarem critérios próprios, lugares e intensidades diferentes, as diferentes idades se relacionam. Os relatos demonstram que, muitas vezes, uma idade pode ser medida pela outra, seja por complementaridade, por inclusão ou por oposição. Então, as diferentes idades não apenas coexistem como acabam agregando sentido umas às outras. Quando uma das pessoas entrevistadas afirma que é na sociabilidade da vida privada que o envelhecimento se manifesta com mais veemência para ela, a entrevistada está dizendo também que o espaço de sociabilidade do trabalho se coloca como imune a esse processo, como lugar onde a idade não importa ou ao menos não deveria importar.

A partir destas análises, nos debruçamos sobre a linearidade da idade. Se as idades não são pontos numa linha reta com uma única direção, já que podem ir e voltar a 
despeito dos números; ainda, se não são intervalos móveis nessa reta, já que, pelos relatos, não é nem reta nem única, o que são essas idades trazidas por nossos entrevistados? Qual é o seu traçado? Estas idades que chamamos de múltiplas são universos de referência que agregam, ao mesmo tempo, valores, modos de agir e maneiras de se localizar no mundo, como num mapa com coordenadas geográficas carregadas de significados e valores com as quais é possível se aproximar de uns lugares e se afastar de outros, se orientar e planejar seus trajetos. As vozes dos entrevistados parecem querer dizer, então, que somos o que fazemos e não quantos anos temos.

\section{CONSIDERAÇÕES FINAIS}

Atualmente o envelhecimento é um tema amplamente discutido em disciplinas como Gerontologia, Antropologia, Psicologia e Sociologia. Nos Estudos Organizacionais, o tópico também tem sido abordado sob a ótica do impacto do fenômeno na esfera do trabalho nas próximas décadas. Temas como estratégias de retenção e motivação, práticas de transferência de conhecimento, estratégias de desenvolvimento e treinamento, conflito geracional, desenvolvimento de carreira e planos de sucessão são alguns deles (HEDGE; BORMAN, 2012). Outro ponto que, embora seja pouco discutido na área de Estudos Organizacionais, não é menos importante é a questão da idade (LAWRENCE, 1996).

Neste trabalho, a questão da idade foi crucial para compreender como os profissionais constroem a noção do envelhecimento. 0 primeiro ponto verificado a partir dos dados foi a ideia de não-naturalidade da identificação etária, ou seja, o não reconhecimento, por parte dos profissionais entrevistados, por sua idade cronológica, mas sim de múltiplas idades que se inter-relacionam no curso de vida do profissional.

0 envelhecimento, por exemplo, pode ser reconhecido pelos entrevistados como uma relação histórica e geracional, que não tem necessariamente a ver com a idade individual, mas que se apresenta como tendência na esfera profissional. Nas entrevistas os indivíduos alegaram, por exemplo, que o mercado imobiliário e o jornalismo teriam rejuvenescido nos últimos anos. Estaria presente, neste sentido, uma idade coletiva. Em outros momentos, o envelhecimento é entendido como uma postura, apontando para valores e modos "corretos" ou esperados para agir, por vezes, contrários ao desejo pessoal. Estaria presente, neste caso, uma idade moral. Por vezes, ainda, o envelhecimento é identificado a partir dos sinais do corpo, independentemente da idade cronológica, indicando, portanto, uma idade corporal revelada pelos profissionais. Os dados demonstraram, ainda, identidades etárias construídas por meio de referências do mundo do trabalho. Identificou-se, então, uma idade profissional, ou seja, uma idade construída profissionalmente que posiciona o indivíduo no mundo do trabalho de acordo com determinados critérios.

Neste contexto, ficou evidente, a partir das entrevistas, que o trabalho é uma importante atividade que, de certa maneira, rejuvenesce os indivíduos. Por outro lado, o não-trabalho surge como imagem negativa aos profissionais mais velhos, pois está associado a elementos como morte, perda de função na sociedade e congelamento. O tópico sobre história e temporalidades também surgiu quando elementos de continuidade, como prosseguir estudando e se aperfeiçoando, foram vistos como garantia de que o envelhecimento não se legitime no espaço de trabalho. Mas, elementos de ruptura, como as demissões, 
acabam por evidenciar o processo de envelhecimento. 0 tópico relacionado à experiência, que é recorrente quando se trata do envelhecimento, também surgiu como um ponto importante nas entrevistas. Para os indivíduos o valor da experiência depende dos outros critérios não-cronológicos, como atualização, adequação e preparo, o que fortalece o conceito de idade profissional proposto neste trabalho. A partir de algumas diferenças entre a realidade profissional do setor público e de empresas privadas, foi possível verificar que a idade profissional se mostra categorizada. Elaboramos, nesse sentido, os conceitos de idade burocrática e idade empresarial, como peculiares aos profissionais que atuam nos respectivos setores.

Este trabalho pretende contribuir para os estudos a respeito do envelhecimento nos Estudos Organizacionais. A contribuição se dá na medida em que a idade cronológica, ainda que amplamente utilizada para capturar o grau em que a pessoa tem progredido no processo de envelhecimento, tem sido repetidamente criticada por estudiosos que demonstram insatisfação com esta variável, uma vez que ela se apresenta como uma medida do tempo e não uma variável psicológica (SCHWALL, 2012). Sugerimos, neste sentido, que sejam considerados os conceitos elaborados neste trabalho e os respectivos critérios que apontam a experiência dos profissionais com o envelhecimento. Afinal de contas, quando a referência do pesquisador, no tratamento de categorias como crianças, jovens ou velhos, é apoiada na idade cronológica ou na aparência de cada um, acaba-se por perder a maleabilidade das formas pelas quais o curso da vida é concebido, como também o sentimento empregado na relação entre grupos etários e sua importância na organização social (DEBERT, 2006).

As conclusões deste trabalho permitem afirmar que os Estudos Organizacionais se constituem como uma abordagem relevante, capaz de colaborar para a compreensão do fenômeno em conjunto com outras lentes e perspectivas. 0 artigo, no entanto, apresenta algumas limitações. Uma delas trata-se da análise em conjunto, considerando os profissionais do sexo feminino e masculino, a respeito do envelhecimento, ainda que estudiosos atentem ao fato de desconsideração de características específicas de cada um deles, abordando-os de forma homogênea (MORI; COELHO, 2004). Além disso, não foram considerados, na análise, dados que poderiam influenciar nos resultados, como o estado civil dos profissionais e a presença de filhos. A pesquisa realizada incita novas investigações a partir da utilização de uma idade subjetiva para abordar o envelhecimento nos estudos sobre trabalho. Sugere-se, ainda, que futuras pesquisas sobre o tópico sejam realizadas, para verificar como a concepção de envelhecimento é construída para profissionais de diferentes gêneros. Considera-se relevante que pesquisas como esta sejam realizadas em outros contextos sociais, a fim de identificar a questão cultural que permeia o fenômeno.

\section{REFERÊNCIAS}

ARMSTRONG-STASSEN, M.; CAMERON, S. Factors related to the career satisfaction of older managerial and professional women. Career Development International, v. 10, n. 3, p. 203-215, 2005.

BENGTSON, V.L. et al. Theories about age and ageing. In: (eds.). Handbook of

theories of ageing. 2 ed. New York: Springer Publishing Co., 2009. 
BURRELL, G; MORGAN, G. Sociological Paradigms and Organisational Analysis. London: Heinemann 1979.

CEPELLOS, V.M. Os sentidos da idade: morte e renascimento no processo de envelhecimento de mulheres executivas. 2016. Tese (Doutorado em Administração de Empresas), Escola de Administração de Empresas de São Paulo da Fundação Getulio Vargas, São Paulo, 2016. Recuperado de <http://bibliotecadigital.fgv.br/dspace/handle/10438/16640>.

CHARMAZ, K. A construção da teoria fundamentada: guia prático para análise qualitativa. Porto Alegre: Artmed. 2009.

CUNLIFFE, A.L. Orientations to Social Constructionism: relationally responsive social constructionism and its implications for knowledge and learning. Management Learning, v. 39, n. 2, p. 123-139. 2008.

. Reflexive Inquiry in Organizational Research: Questions and Possibilities. Human Relations, v. 56, n. 8, p. 983-1003, 2003.

DEBERT, G.G. Antropologia e o estudo dos grupos e das categorias de idade. In: BARROS, M.M.L. de. (org.). Velhice ou Terceira Idade? Rio de Janeiro: FGV. 2006.

FORTES, M. Age, generation, and social structure. In: KERTZER, D.; KEITH, J. Age and anthropological theory. Ithaca: Cornell University Press. 1984.

FRANÇA, L.H. de F.P. O envelhecimento populacional e seu reflexo nas organizações: a importância da educação ao longo da vida. Boletim Técnico do Senac, Rio de Janeiro, v. 37, n. 2, 2011.

FUNDO DE POPULAÇÃO DAS NAÇÕES UNIDAS - FNUAP. Envelhecimento no Século XXI: celebração e desafio. Nova York. 2012.

GANS, D. et al. The future of theories of ageing. In: BENGTSON, V.L. et al. (eds.). Handbook of theories of ageing. 2 ed. New York: Springer Publishing Co., 2009.

GAVRILOV, L.A; HEUVELINE, P. Ageing of population. In: DEMENY, P.; MCNICOLL, G. The Encyclopedia of Population. New York: Macmillan Reference, 2003.

GIAMBIAGI; F.; TAFNER, P. Demografia, a ameaça invisível: o dilema previdenciário que o Brasil de recusa a encarar. Rio de Janeiro: Elsevier. 2010.

HEDGE, J.W.; BORMAN, W.C. Work and Ageing: introduction. In: HEDGE, J.W.; BORMAN, W.C. (eds.). The Oxford Handbook of Work and Ageing. Oxford University Press: Oxford, 2012. p. 3-8.

HENKENS, K. Stereotyping Older Workers and Retirement: The Managers' Point of View. Canadian Journal on Ageing, v. 24, n. 4, p. 353-366, 2005.

INSTITUTO BRASILEIRO DE GEOGRAFIA E ESTATÍSTICA - IBGE. Síntese de Indicadores Sociais: uma análise das condições de vida da população brasileira. Rio de Janeiro: IBGE, 2013.

KOHLI, M; MEYER, J.W. Social structure and social construction of life stages. Human Development, v. 29, n. 3, p. 145-149, 1986. 
KOOJI, D.T.A.M. et al. Manageing ageing workers: a mixed methods study on bundles of HR practices for ageing workers. The International Journal of Human Resource Management, v. 25, n. 15, p. 2192-2212, 2014.

LAWRENCE, B.S. Interest and indifference: the role of age in the organizational sciences. Research in personnel and human resources management, v. 14, p. 1-59, 1996.

NG, T.W.H.; FELDMAN, D.C. Ageing and participation in career development activities. In: HEDGE, J.W.; BORMAN, W.C. (eds.). The Oxford Handbook of Work and Ageing. Oxford University Press: Oxford, 2012.

LOCATELLI, P.A.P.C.; FONTOURA, D. dos S. Envelhecimento Populacional e os Estudos em Administração. Revista Eletrônica Gestão e Sociedade. Belo Horizonte, v. 7, n. 17, p. 273-300, 2013.

LORETTO, W.; WHITE, P. Employers' attitudes, practices and policies toward older workers. Management School and Economics, University of Edinburgh, Human Resource Management Journal, v. 16, n. 3, p. 313-330, 2006.

MOL, A. Ontological politics: a word and some questions. The Sociological Review, v. 47, n. S1, p. 74-89. 1999.

MORGAN, G.; SMIRCICH, L. The case for Qualitative Research. Academy of Management Review, v. 5, n. 4, 1980.

MORI, M.E.; COELHO, V.L.D. Mulheres de corpo e alma: Aspectos Biopsicossociais da Meia-Idade Feminina. Psicologia: Reflexão e Crítica, Brasília, n. 17, v. 2, p. 177-187. 2004.

NASCIMENTO, R.P. et al. 'Trabalhar é manter-se vivo': Envelhecimento e Sentido do TrabaIho para Docentes do Ensino Superior. Sociedade, Contabilidade e Gestão, v. 11, n. 2, p. 118-138, 2016.

NONATO, F.J.A.P. et al. O perfil da força de trabalho brasileira: trajetórias e perspectivas. Boletim Mercado de Trabalho - Conjuntura e Análise, v. 51, p. 30-41, 2012.

PHILLIPS, D.R.; SIU, O.-L. Global Ageing and Ageing Workers. In: HEDGE, J.W.; BORMAN, W.C. (eds.). The Oxford Handbook of Work and Ageing. Oxford University Press: Oxford, 2012.

SCHWALL, A.R. Defining age and using age-relevant constructs In: HEDGE, J.W.; BORMAN, W.C. (eds.). The Oxford Handbook of Work and Ageing. Oxford University Press: Oxford, 2012.

SPINK, M.J.; MEDRADO, B. Produção de sentidos no cotidiano: uma abordagem teórico- metodológica para análise das práticas discursivas. In: SPINK, M.J. (org.). Práticas Discursivas e Produção de Sentidos no Cotidiano: aproximações teóricas e metodológicas. 2. ed. São Paulo: Cortez, 2000. p. 41-61.

STRAUSS, A.; CORBIN, J. Pesquisa Qualitativa: Técnicas e procedimentos para o desenvolvimento de teoria fundamentada. Porto Alegre: Artmed, 2008.

TAYLOR, P.; WALKER, A. Employers and older workers: attitudes and employment practices. Ageing \& Society. v. 18, n. 6, p. 641-58, 1998. 
UNITED NATIONS. World Population Nation. New York: UN. 2015.

VASCONCELOS, A.F. The contemporary experience of work: older workers'perceptions. Management Research Review, v. 38, n. 4, p. 381-403, 2015.

Data de Submissão: 10/10/2016.

Data de Aprovação: 07/02/2017. 